Diabetologia (1981) 21:569-574

\title{
Hyperglycaemia Induced by Glucose Infusion in the Unrestrained Pregnant Rat During the Last Three Days of Gestation: Metabolic and Hormonal Changes in the Mother and the Fetuses
}

\author{
A. Ktorza, J. R. Girard, M. F. Kinebanyan and L. Picon \\ Laboratoire de Physiologie du Développement, Laboratoire associé au C. N. R. S. No 307 , Université Paris VII \\ and Laboratoire de Physiologie du Développement Collège de France, France
}

\begin{abstract}
Summary. Continuous glucose infusion was used to induce mild hyperglycaemia in unrestrained pregnant rats during the last three days of pregnancy. Control pregnant rats were infused with distilled water. Fetuses were studied after normal or prolonged pregnancy. Fetuses from glucose-infused rats, compared with controls, showed higher plasma glucose levels, increased plasma insulin and lower plasma glucagon concentrations. Pregnancy prolonged until day 23.5 resulted in a rise in the glucagon/insulin ratio from 6.5 to 67 in fetuses from control rats and from 1.3 to 13 in fetuses from glucose-infused rats. Concurrently in fetuses from control rats, liver phosphoenolpyruvate carboxykinase activity increased markedly and liver glycogen stores decreased sharply. In fetuses from glucose-infused rats, liver phosphoenolpyruvate carboxykinase activity rose and glycogen content decreased, but to a lesser extent. These results show that both the A and B cells of the rat fetal pancreas are sensitive to chronic glucose stimulation.
\end{abstract}

Key words: Glucose infusion, pregnant rats, prolonged pregnancy, fetus, plasma insulin, plasma glucagon, liver phosphoenolpyruvate carboxykinase, liver glycogen.

The effects of maternal hyperglycaemia on fetal growth and fetal insulin secretion are still a matter of controversy. Two types of approach have been widely used. Diabetes has been induced in rats by injecting alloxan or streptozotocin before [13,23,27] or during pregnancy $[2,9]$. Hyperglycaemia caused by alloxan or streptozotocin is usually severe and difficult to control. Moreover, mild or severe diabetes induced by streptozotocin produces quite different effects on fetal growth and fetal insulin secretion $[2,13,31]$. Hyperglycaemia has also been induced by injecting or infusing glucose for a short time into pregnant rats in order to study the effects of hyperglycaemia on fetal insulin secretion [12]. However, these experiments do not take into consideration the consequences for the fetus of long-term exposure to high plasma glucose levels.

We have used a technique [18] that allows continuous infusion of glucose in chronically catheterized conscious and unrestrained pregnant rats with carefully controlled hyperglycaemia for several days in rats living in conditions as close to normal as possible. This technique also avoids the use of diabetogenic drugs which could have some side effects on the fetus and on the placenta $[1,27]$.

The present study was undertaken in fetuses at term to evaluate the consequences of a long lasting hyperglycaemia, on insulin and glucagon secretion, and glucose metabolism in the liver. The effect of hyperglycaemia on post-mature fetuses was also investigated, since it has been reported that, in the rat fetus, prolonged pregnancy induces a rise in the plasma glucagon/insulin ratio [25] associated with a fall in liver glycogen content and a rise in the activity of a key regulatory enzyme of gluconeogenesis: phosphoenolpyruvate carboxykinase (PEPCK) (E.C.4.1.1.32) [26].

\section{Materials and Methods}

\section{Animals}

Albino rats of the Sherman strain, bred in the laboratory, were fed ad libitum with pelleted chow (UAR B-03). Females were caged with a male for one night $(17.00-09.00 \mathrm{~h})$ and pregnancy was de- 
Table 1. Plasma glucose, IRI and IRG levels, liver PEPCK activity and glycogen stores in control and glucose-infused pregnant rats

\begin{tabular}{|c|c|c|c|c|c|c|}
\hline & Day of gestation & $\begin{array}{l}\text { Plasma glucose } \\
(\mathrm{mmol} / \mathrm{l})\end{array}$ & $\begin{array}{l}\text { Plasma IRI } \\
(\mathrm{mU} / 1)\end{array}$ & $\begin{array}{l}\text { Plasma IRG } \\
(\mathrm{pg} / \mathrm{ml})\end{array}$ & $\begin{array}{l}\text { Liver PEPCK activity } \\
\left(\text { nmol h}^{-1} \text { mg protein }^{-1} \text { ) }\right.\end{array}$ & $\begin{array}{l}\text { Liver glycogen } \\
\text { (mg/g of liver) }\end{array}$ \\
\hline \multirow{3}{*}{ Control rats } & 21.5 & $5.78 \pm 0.67$ & $\begin{array}{l}49 \pm 7 \\
(6)\end{array}$ & $245 \pm 40$ & $166 \pm 32$ & $\begin{array}{c}22.3 \pm 0.4 \\
(6)\end{array}$ \\
\hline & 22.5 & $\begin{array}{l}5.17 \pm 0.50 \\
(7)\end{array}$ & $\begin{array}{c}45 \pm 7 \\
(5)\end{array}$ & $300 \pm 37$ & $190 \pm 40$ & $27.1 \pm 0.6$ \\
\hline & 23.5 & $\begin{array}{c}5.23 \pm 0.39 \\
(5)\end{array}$ & $\begin{array}{c}33 \pm 5 \\
(5)\end{array}$ & $\begin{array}{c}312 \pm 29 \\
(5)\end{array}$ & $\begin{array}{c}184 \pm 30 \\
(5)\end{array}$ & $\begin{array}{c}20.1 \pm 0.5 \\
(5)\end{array}$ \\
\hline \multirow{3}{*}{$\begin{array}{l}\text { Glucose-infused } \\
\text { rats }\end{array}$} & 21.5 & $\begin{array}{c}10.50 \pm 1.67^{\mathrm{a}} \\
(11)\end{array}$ & $340 \pm 18^{\mathrm{a}}$ & $96 \pm 16^{a}$ & $48 \pm 10^{\mathrm{a}}$ & $96.1 \pm 1.5^{b}$ \\
\hline & 22.5 & $11.11 \pm 1.56^{\mathrm{a}}$ & $\begin{array}{c}268 \pm 12^{a} \\
(6)\end{array}$ & $100 \pm \frac{17^{a}}{(6)}$ & $48 \pm 7^{a}$ & $93.0 \pm 1.5^{b}$ \\
\hline & 23.5 & $\begin{array}{c}11.56 \pm 0.67^{\mathrm{a}} \\
(6)\end{array}$ & $367 \pm 24^{a}$ & $94 \pm 16^{a}$ & $56 \pm 9^{a}$ & $93.2 \pm 1.6^{\mathrm{b}}$ \\
\hline
\end{tabular}

Values are expressed as mean \pm SEM with number of determinations in parentheses. Significant differences from controls are indicated by: ${ }^{\mathrm{a}} p<0.001 ;{ }^{\mathrm{b}} p<0.01$

tected by abdominal palpation 14 days later. In our colony, birth occurred 22 days after mating.

In pregnant rats sacrificed on days 22.5 and 23.5 post-coitum, parturition was prevented by injecting progesterone $2.5 \mathrm{mg}$ daily (Lutogyl Roussel, France). The treatment was started on day 20.5 . No progesterone was injected into rats sacrificed on day 21.5 postcoitum.

The flexible technique for long-term infusions in unrestrained rats developed by Nicolaidis et al. [18] was used for glucose infusions. Under Ketamine anaesthesia (Imalgène, Mérieux, France; $125 \mathrm{mg} / \mathrm{kg} \mathrm{IP}$ ), each pregnant rat was fitted with an indwelling jugular vein catheter of silicone rubber (Silastic, Dow Corning, USA), connected to a terminal Tygon tubing fixture maintained on the top of the skull with dental cement ("Pennwalt SS White", Philadelphia, Penn., USA). Rats were housed individually in cylindrical Plexiglas cages and were permanently connected to a peristaltic pump (Minipuls 2, Gilson, France) via polyethylene tubing and a watertight swivel [18]. The system had minimal inertia and responded to every movement of the rats. In all cases, pregnant rats were continuously infused. The infusion period began day 1 after surgery, and lasted for 3 days until the removal of the fetuses. Hypertonic (30\%) sterile glucose (Chaix et Dumarais, France) was infused at the rate of $39 \mathrm{ml} /$ day. Controls were infused with sterile distilled water (Chaix et Dumarais, France). Distilled water was chosen rather than isotonic saline to avoid sodium overload in controls. Since the infusion rate was very low compared with the blood flow rate in the superior vena cava, haemolytic disorders were theoretically ruled out and indeed never observed. For each group, 5-11 animals were used.

\section{Samples}

Plasma glucose of infused rats was measured daily on blood samples collected from the tail vein. After maternal anaesthesia (Imalgène $125 \mathrm{mg} / \mathrm{kg} \mathrm{IP}$ ), the fetuses were successively exteriorized from the uterus, leaving placenta and umbilical cord in situ in order to maintain normal feto-maternal exchanges. Blood was collected from the axillary vessels and the livers were rapidly removed, weighed and, either frozen in liquid nitrogen for glycogen determination, or homogeneized in $0.5 \mathrm{~mol} / 1$ maleate buffer $(\mathrm{pH} 6.5)$ for PEPCK determination. Fetuses were then removed and weighed, the total weight value taking into account the weight of blood and liver samples. In some cases, plasma or organs from several fetuses of the same litter had to be pooled, especially for hormone determi- nation. Mothers were infused throughout the period of removal of the fetuses.

Plasma glucose was determined by the glucose oxidase technique on $10 \mu \mathrm{l}$ samples using a glucose analyzer (Beckman, Palo Alto, USA).

Plasma immunoreactive insulin (IRI) was estimated using purified rat insulin as standard antibody (R 171, Novo, Copenhagen, Denmark) to human insulin [30], and porcine mono-iodinated ${ }^{125} \mathrm{I}-$ insulin [8]. Silicate was used to separate free from bound hormone [29]. The method allowed the determination of $6 \mathrm{mU} / 1(0.25 \mathrm{ng} /$ $\mathrm{ml}$ ) with a coefficient of variation within and between assays of $10 \%$.

Plasma immunoreactive glucagon (IRG) was measured on unextracted samples using the glucagon antibody $30 \mathrm{~K}$, porcine mono-iodinated ${ }^{125} \mathrm{I}$-glucagon as tracer [19] and porcine glucagon as standard (B 66 K 1070, Dr. J. Schlichtkrull, Novo, Copenhagen, Denmark) and a charcoal-dextran separation technique [8]. The coefficient of variation within and between assays was $10 \%$.

Glycogen concentration in the liver was determined by the amylo-glucosidase technique of Roehring and Allred [28] and was expressed as $\mathrm{mg} / \mathrm{g}$ of liver.

Soluble PEPCK was measured according to the method of Ballard and Hanson [4] on the $100,000 \mathrm{~g}$ supernatant of the homogenates and activity was measured by the conversion of $\mathrm{NaH}^{14} \mathrm{CO}_{3}$ (Radiochemical Centre, Amersham, UK) to malate expressed in $\mathrm{nmol} \mathrm{h}^{-1} \mathrm{mg}$ protein ${ }^{-1}$. Proteins were determined by the method of Lowry et al. [16].

Results are expressed as mean \pm SEM. Significance of differences between means were evaluated by Student's unpaired t-test. Statistical correlations were performed by the classical least squares procedure.

\section{Results}

\section{Effect of Hyperglycaemia on Pancreatic Hormones and Liver Metabolism During the Last 3 Days of Gestation}

Mild hyperglycaemia (approximately $12 \mathrm{nmol} / 1$ ) was maintained in pregnant rats throughout the period of infusion with glucose and a highly significant differ- 


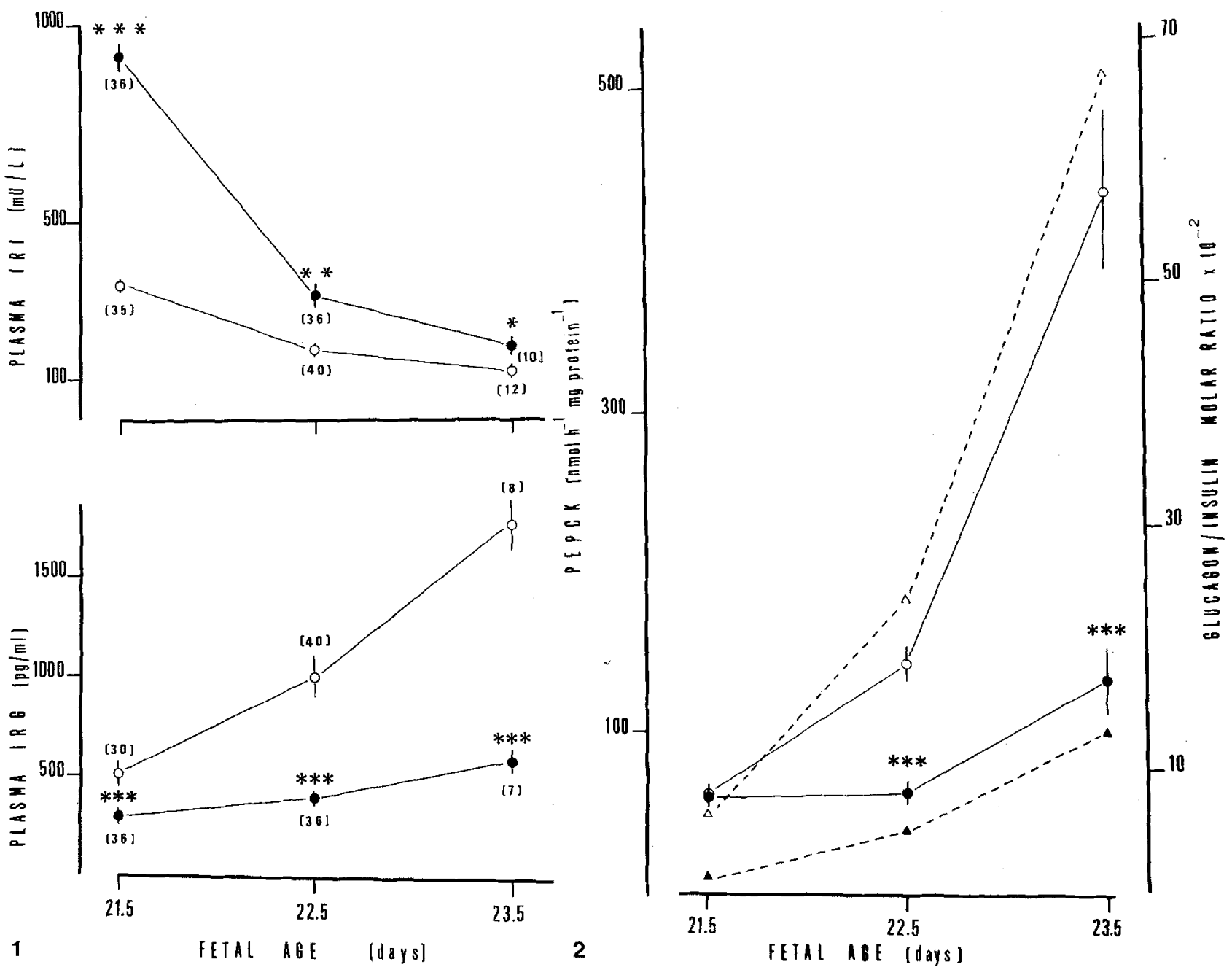

Fig. 1. Plasma IRI and IRG in term and post-mature fetuses. Vertical lines $=$ mean \pm SEM with number of determinations in parentheses. $*^{* *} p<0.001 ; * *<0.01{ }^{*} p<0.05$. (significant difference between controls and glucose-infused). 0 - $0=$ Fetuses from control rats; $\longrightarrow=$ Fetuses from glucose-infused rats

Fig. 2. Evolution during prolonged pregnancy of the fetal glucagon insulin ratio $(\Delta-\Delta$ : fetuses from control rats; $\mathbf{\Delta}-\mathbf{\Delta}$ : fetuses from glucose-infused rats) and of the fetal liver PEPCK activity ( $\bigcirc-0$ : fetuses from control rats; $\bullet$ : fetuses from glucose-infused rats). Each data point is the mean of $10-30$ observations.

*** $p<0.001$ (significant difference between controls and glucose-infused rats)

ence in plasma glucose level existed between glucoseinfused rats and control rats $(p<0.001$; Table 1$)$.

In term, as well as in post-mature pregnant rats, the differences in plasma glucose level between control and glucose-infused rats were associated with hormonal and metabolic changes. In glucose-infused rats, compared with controls, plasma IRI levels were increased and plasma IRG levels were decreased; concurrently, liver PEPCK activity was decreased and glycogen concentration was increased (Table 1). Food intake was much reduced in glucose-infused rats $(15.6 \pm 0.2 \mathrm{kcal} /$ day, $n=22)$ compared with control rats $(67.3 \pm 1 \mathrm{kcal} / \mathrm{day}, n=17)$.

\section{Effect of Hyperglycaemia on Pancreatic Hormones and Liver Metabolism in the Fetuses During the Last 3 Days of Gestation}

Maternal hyperglycaemia induced by glucose infusion was reflected in both term and post-mature fetuses. Plasma glucose levels on days 21.5, 22.5 and 23.5 of pregnancy were respectively: $4.44 \pm 0.17(n=$ $90), 4.39 \pm 0.60(n=34)$ and $3.11 \pm 0.18 \mathrm{mmol} / \mathrm{l}$ $(n=31)$ in fetuses from control rats, and $9.78 \pm 0.39$ $(n=40), 9.22 \pm 0.39(n=40)$ and $9.00 \pm 0.56 \mathrm{nmol} / 1$ $(n=22)$ in fetuses from glucose-infused rats. Regardless of gestational age, the difference between fetuses 
from glucose-infused rats and control rats was highly significant $(p<0.001)$.

The level of IRI in the plasma of 21.5 day-old fetuses from glucose-infused rats was much higher than in 21.5 day-old fetuses from control rats $(p<0.001)$. This difference persisted in 22.5 and 23.5 day-old post-mature fetuses but, in both groups, a decrease in the plasma IRI level was observed with advancing post-maturity (Fig. 1). The level of plasma IRG was lower in fetuses from glucose-infused rats than in fetuses from control rats. However it increased in fetuses of both groups with the prolongation of pregnancy (Fig. 1).

The glucagon/insulin ratio always increased during post-maturity but was much lower in fetuses from glucose-infused rats than in fetuses from control rats (Fig. 2).

Fetal liver PEPCK activity was very low in 21.5 day-old fetuses in both groups; it increased in 22.5 day-old fetuses from control rats and rose markedly on day 23.5 post-coitum. In fetuses from glucose-infused rats, liver PEPCK activity remained unchanged on day 22.5 post-coitum and increased only twofold on day 23.5 (Fig. 2). When liver PEPCK activity was plotted against the glucagon/insulin ratio in fetuses from both control and glucose-infused rats, a linear correlation was found between the two parameters $(y=5.4 x+36 ; n=100 ; r=0.9 ; p<0.001)$.

From day 21.5 to day 23.5 of pregnancy, liver glycogen concentrations were respectively: $110 \pm 2(n=$ $15), 85 \pm 2(n=35)$ and $22 \pm 1 \mathrm{mg} / \mathrm{g}$ liver $(n=35)$ in fetuses from control rats and $116 \pm 3(n=20), 91 \pm 4$ $(n=20)$ and $60 \pm 1 \mathrm{mg} / \mathrm{g}$ liver $(n=22)$ in fetuses from glucose-infused rats. The difference between the two groups was highly significant on day 23.5 postcoitum $(p<0.001)$.

Body weight on days $21.5,22.5$ and 23.5 of pregnancy was respectively: $4.37 \pm 0.06(n=90), 4.95 \pm$ $0.08(n=66)$ and $5.70 \pm 0.09 \mathrm{~g}(n=57)$ in fetuses from control rats and $4.23 \pm 0.06(n=97), 5.02 \pm$ $0.09(n=57)$ and $6.03 \pm 0.12 \mathrm{~g}(n=31)$ in fetuses from glucose-infused rats. The difference between the two groups was not significant, except on day 23.5 post-coitum $(p<0.05)$.

\section{Discussion}

One day after surgery, the pregnant rats recovered normal food intake. The concentration of glucose in plasma of control rats, during the last 3 days of pregnancy were very similar to the values previously reported [7]. When pregnant rats were infused with glucose, their glycaemia was about twice that found in control rats. Increased plasma insulin levels, de- creased plasma glucagon levels, reduced liver PEPCK activity and enhanced liver glycogen stores in glucose-infused rats were consistent with hyperglycaemia. Since in both control and glucose infused rats, the above plasma and hepatic parameters did not change significantly with post-maturity, it can be assumed that the progesterone treatment was without effect in these parameters. The dramatic drop in oral food intake in glucose-infused rats is in agreement with the 'glucostatic' theory developed by Mayer [17]. However, if calories supplied by the parenteral nutrition are taken into consideration, the total intake of calories was not significantly different between control and glucose-infused rats.

In agreement with previous reports [7, 22], plasma glucose concentrations in term and post-mature fetuses in both groups were lower in the fetuses than in their mother at every gestational age. Maternal hyperglycaemia, induced by glucose infusion, enhanced the plasma glucose level in fetuses. Hence sustained hyperglycaemia of pregnant rats and the steady hyperglycaemia in their fetuses, regardless of fetal age, appears to be a useful system to study the response to glucose of fetal pancreas in vivo as an alternative to the induction of experimental diabetes in the mothers.

The plasma insulin levels found in fetuses at term from control rats are in accordance with previous studies showing high levels of plasma insulin in rat fetuses at term [7]. The higher levels of plasma insulin in fetuses from hyperglycaemic mothers confirm that fetal B cells are able to respond to glucose stimulation. Similar conclusions were obtained by Kervran and Girard [12], using short-term glucose infusions in pregnant rats. In contrast, other reports showed that acute glucose loads failed to increase fetal plasma insulin levels $[3,6]$.

The finding of high plasma glucagon levels in fetuses at term from control rats is also in agreement with previous reports [25]. The level of plasma glucagon in fetuses at term from glucose-infused rats was significantly lower than in fetuses from control rats. It has been previously shown that acute increase in plasma glucose concentration, induced by short-term glucose infusion in the mother, failed to decrease fetal plasma glucagon level [10]. From these experiments, it was concluded that the A cells of the fetal pancreas were insensitive to short-term hyperglycaemia. Our study shows that the fetal A cell is indeed glucoseresponsive, provided that glucose stimulation is of sufficient duration.

Decrease of plasma insulin levels and increase of plasma glucagon levels in fetuses from control rats with advancing post-maturity are in agreement with previous data [25]. In post-mature fetuses from glu- 
cose-infused rats, although the same hormonal changes occurred, plasma insulin levels remained higher and plasma glucagon levels were lower than in fetuses from control rats. The hormonal modifications during post-maturity might possibly be explained by adrenergic activation correlating with fetal stress during post-maturity. Accordingly, it has been shown previously that the increase of insulin secretion induced by glucose can be prevented by adrenaline [5].

These hormonal changes were reflected strikingly in the fetal liver PEPCK activity (Fig. 2) and our results suggest that a fall in the plasma glucagon/insulin ratio can partially prevent PEPCK induction. The fact that fetuses with similar glucose levels exhibited very different PEPCK activities and that, regardless of plasma glucose concentration, a close relationship was found between PEPCK activity and the glucagon/insulin ratio, indicates that the fetal liver PEPCK induction is mediated by hormonal changes rather than directly related to hyperglycaemia. Accordingly, previous reports demonstrated that sugars, such as galactose or mannose, able to block PEPCK activity were also able to stimulate insulin secretion [14], whereas sugars that did not stimulate insulin secretion (ribose, 2-deoxy-glucose) had no effect on PEPCK activity. Whatever the primary cause of PEPCK activation, its metabolic effect on the fetus seems rather limited since it was concluded from experiments in vivo, carried out both in term and post-mature fetuses, that PEPCK induction did not result in activation of gluconeogenesis [15].

In 21.5 day-old fetuses from glucose-infused rats, compared with fetuses from control rats, hyperglycaemia and a low glucagon/insulin ratio did not result in a significant increase of liver glycogen stores. It is well known that important glycogen storage occurs during the last days of pregnancy in the rat fetus [11]. Possibly, the already high level of liver glycogen content in the normal term rat fetus cannot be further enhanced. Nevertheless, the decreased concentration of fetal liver glycogen from day 21.5 to day 23.5 of pregnancy seems to be well related to plasma glucose and hormonal changes, since the fall in glycogen concentration in 23.5 day-old fetuses from control rats correlates with a dramatic rise in the glucagon/insulin ratio and a decreased glycaemia, whereas, in fetuses from glucose-infused rats of the same age, showing higher plasma glucose levels and a much lower glucagon/insulin ratio, the decrease in liver glycogen concentration occurs to a much lesser extent.

The hormonal and metabolic changes reported in the post-mature fetuses are unlikely to be due to the progesterone injected into the mothers, as it has been previously shown in fetuses at term, that progesterone injected into the pregnant rat during the last 3 days of pregnancy had no effect on plasma glucose, IRI, IRG, liver PEPCK and glycogen [24]. Fetal hyperinsulinism and hyperglycaemia did not induce a significant increase in fetal body weight until day 23.5 postcoitum. Conflicting results have been published concerning the effects of maternal diabetes in the rat on the body weight of the fetuses [2, 23,31]. This is in contrast with the situation in the offspring of women with mild untreated diabetes where there is usually an increase of body weight, mainly related to excessive fat deposition [20]. The poor adipose development in rat fetuses at term might be a possible explanation for this discrepancy.

Acknowledgements. We gratefully acknowledge the helpful advice of Dr. S. Nicolaidis, Laboratoire de Neurophysiologie sensorielle et comportementale, Collège de France, concerning the infusion technique, Dr. A. Kervran for the determination of plasma insulin concentration in 21.5 day-old fetuses and Dr. G. Rosselin, INSERM. U.55, for the gift of iodinated-insulin.

\section{References}

1. Abramovici A, Sporn J, Prager R, Shaltiel A, Laron Z, Liban E (1978) Glycogen metabolism in the placenta of streptozotocin diabetic rats. Horm Metab Res 10: 195-199

2. Aerts L, Van Assche A (1977) Rat foetal endocrine pancreas in experimental diabetes. J. Endocrinol 73: 339-346

3. Asplund K, Westman S, Hellerström C (1969) Glucose stimulation of insulin secretion from the isolated pancreas of foetal and newborn rats. Diabetologia 5:260-262

4. Ballard F-J, Hanson R-W (1967) Phosphoenolpyruvate carboxykinase and pyruvate carboxylase in developing rat liver. Biochem J 104: 866-871

5. Cerasi E, Luft R, Efendic S (1971) Antagonism between glucose and epinephrine regarding insulin secretion. Acta Med Scand 190: $411-417$

6. Clark C-M Jr, Cahill G-F Jr, Soeldner J-S (1968) Effects of exogenous insulin on the rate of fatty acid synthesis and glucose $\mathrm{C}^{14}$ utilization in the twenty day rat fetus. Diabetes 17:362-368

7. Felix J-M, Jacquot R, Sutter B-C-J (1969) Insulinémies foetales et maternelles chez le rat. Horm Metab Res 1:41-42

8. Freychet P, Roth J, Neville D-M Jr (1971) Monoiodoinsulin: demonstration of its biological activity and binding to fat cells and liver membranes. Biochem Biophys Res Commun 43: 400-408

9. Golob E-K, Rishi S, Becker K-L, Moore C, Shah N (1970) The effect of streptozotocin-induced diabetes ón pancreatic insulin content of the fetuses. Diabetes 19:610-613

10. Girard J-R, Cuendet G-S, Marliss E-B, Kervran A, Rieutort M, Assan R (1973) Fuel hormones and liver metabolism at term and during the early postnatal period in the rat. J Clin Invest 52: 3190-3200

11. Jost A, Jacquot R (1958) Sur le rôle de l'hypophyse des surrénales et du placenta dans la synthèse de glycogène dans le foie foetal de lapin et de rat. CR Acad Sci (Paris) 247:2459-2462

12. Kervran A, Girard J-R (1974) Glucose-induced increase of plasma insulin in the rat foetus in utero. J Endocrinol 62: $545-551$

13. Kervran A, Guillaume M, Jost A(1978) The endocrine pancreas 
of the fetus from diabetic pregnant rat. Diabetologia 15: 387-393

14. Lambert A-E (1970) Biochemical and morphological studies of cultured fetal rat pancreas. Thèse Université de Genève

15. Le Provost E, Portha B, Cros J-C, Picon L (1980) Postmaturity in the rat: glucose metabolism in the fetus and the neonate. Pediatr Res 14: 793-798

16. Lowry O-H, Rosenbrough N-Y, Farr A-L, Randall R-I (1951) Protein measurement with the Folinphenol reagent. J Biol Chem 193:265-275

17. Mayer J (1955) Regulation of energy intake and the body weight. The glucostatic theory and the lipostatic hypothesis. Ann NY Acad Sci 63: 15-42

18. Nicolaïdis S, Rowland N, Meile M-J, Marfaing-Jallat P, Pesez A (1974) A flexible technique for long term infusions in unrestrained rats. Pharmacol Biochem Behav 2: 131-136

19. Nottey J-J, Rosselin G (1971) Monoiodoglucagon: preparation isolement identification contrôle radio-immunologique. CR Acad Sci (Paris) 273:2118-2121

20. Osler M (1960) Body fat of newborn infants in diabetic mothers. Acta Endocrinol 34:227-286

21. O'Sullivan J-B, Gellis S-S, Tenney B-O (1966) Gestational blood glucose levels in normal and potentially diabetic women related to the birth weight of their infants. Diabetes $15: 466-470$

22. Picon L, Montane M (1968) Glycémies foetales et maternelles chez la rate à divers stades de la gestation. Action de l'insuline injectée au foetus sur la glycémie. CR Acad Sci (Paris) 267: $860-863$

23. Pitkin R-M, Van Horden D-E (1974) Fetal effects of maternal streptozotocin-diabetes. Endocrinology 94: 1247-1253

24. Portha B, Rosselin G, Picon L (1976) Postmaturity in the rat: impairment of insulin glucagon and glycogen stores. Diabetologia $13: 429-439$
25. Portha B, Picon L, Rosselin G (1978) Postmaturity in the rat: high plasma glucagon levels in the fetus and the newborn. $J$ Endocrinol 77: 153-154

26. Portha B, Le Provost E, Picon L, Rosselin G (1978) Postmaturity in the rat: phosphorylase glucose 6-phosphatase and phosphoenolpyruvate carboxykinase activities in the fetal liver. Horm Metab Res 10: 141-144

27. Prager R, Abramovici A, Liban E, Laron Z (1974) Histopathological changes in the placenta of streptozotocin induced diabetic rat. Diabetologia 10: 89-91

28. Roehring K-L, Allred J-B (1974) Direct enzymatic procedure for the determination of liver glycogen. Anal. Biochem 58: 414-421

29. Rosselin G, Assan R, Yalow R-S, Berson S-A (1966) Separation of antibody bound and unbound peptide hormones with iodine 131 by talcum powder and precipitated silica. Nature 212: 355-357

30. Rosselin G, Dolais J (1967) Application de la méthode radioimmunologique au dosage de l'insuline humaine et au dosage de l'hormone folliculo-stimulante (H. FSH). Monographie Ann Sté Fse Biol Clin 1: 189-217

31. Solomon $F(1959)$ Embryomegaly and increased fetal mortality in pregnant rats with mild alloxan diabetes. Diabetes $8: 45-50$

Received: 18 December 1980

and in revised form: 23 June 1981

\section{A. Ktorza}

Laboratoire de Physiologie du Développement

Laboratoire associé au C.N.R.S. (No 307)

Université Paris VII

2, Place Jussieu

F-75251 Paris Cedex 05, France 